\title{
Empirically derived profiles of homework purposes in eleventh grade students: a latent profile analysis
}

\author{
Jianzhong $X \mathrm{u}^{1,2}$ (D) \\ Accepted: 9 June 2021 / Published online: 12 June 2021 \\ (C) The Author(s), under exclusive licence to Springer Science+Business Media, LLC, part of Springer Nature 2021
}

\begin{abstract}
Informed by expectation-value theory and related literature, the goal of the current investigation was to identify profiles of students drawn from three purposes of homework (academic, self-regulatory, and approval-seeking). Participants were 750 eleventh-grade students in China. Results from latent profile analysis (LPA) revealed identified four different profiles of students: Very Low Profile (very low in all purposes; 5.73\%), Low Profile (low in all purposes; 30.40\%), Moderate Profile (moderate in all purposes; 54.40\%), and High Profile (high in all purposes; 9.47\%). Results further revealed that student gender was associated with profile membership. Finally, profile membership was significantly related to homework effort and completion (with a medium effect size) in that, in general, the higher the homework purposes, the higher the homework effort and homework completion.
\end{abstract}

Keywords Homework purpose $\cdot$ Latent profile analysis $\cdot$ Homework effort $\cdot$ Homework completion $\cdot$ High school

As students are frequently assigned homework for almost every class they take (Corno, 2011), homework is a common and widespread achievement-related task around the world (Cooper et al., 2006; Fan et al., 2017) and an important part of daily life for many students and their families (Corno \& Xu, 2004; Fernández-Alonso et al., 2015). Given that task value learners place on the outcomes of a task can have powerful influences on task effort, persistence, and completion (Eccles, 1983; Wigfield et al., 2015), the value of homework perceived by students has important implications for homework practice and research (Rodríguez et al., 2020; Xu, 2020). Previous research, however, uses a variable-centered approach with its emphasis on the value of homework perceived by adults (Cooper et al., 2006; Rosário et al., 2019; Van Voorhis, 2004; $\mathrm{Xu}, 2005)$.

To address this important gap in extant literature on homework, the current study adopted a person-centered approach with its focus on the value of homework perceived by students

Jianzhong Xu

jx18@colled.msstate.edu; jianzhongxu18@gmail.com

1 Department of Counseling, Educational Psychology, and Foundations, Mississippi State University, P.O. Box 9727 , Mississippi State, MS 39762, USA

2 University of Macau, Macau, China themselves. Specifically, it examined (a) whether there are empirically derived profiles of students with a certain combination of homework purposes, and (b) whether these profiles are significantly related to differences in homework behavior. This line of research is particularly important, as previous qualitative studies with elementary and secondary school students (Xu \& Corno, 1998; Xu \& Yuan, 2003) suggests that students can endorse different homework purposes at the same time. Recent quantitative studies (Sun et al., 2020a, b; Xu, 2021) have investigated multiple homework purposes perceived by students but treated these purposes as individual variables without concerning about their interplay. Yet, results from these studies have revealed that all homework purposes were correlated, further suggesting the possibility that students may endorse multiple homework purposes simultaneously.

Identification of homework purpose profiles may provide new sights on the ways homework purposes function together and the influences of these profiles on other key constructs in the homework process. Thus, a person-centered approach allows researchers to examine the interplay among different homework purposes. Hence, if the pattern of different homework purposes is important in predicting homework behavior (e.g., homework effort and completion), a person-centered approach may be more likely to detect the relationships that multiple homework purposes have with homework behavior than a variable-centered approach. Furthermore, a person- 
centered approach enables teachers, parents, and researchers to consider how students make use of multiple homework purposes to follow through their homework assignments.

In particular, there is a need to use a person-centered approach to reveal the existence of different profiles of math homework purposes for high school students. First, math is a highly important, yet difficult, subject around the world (e.g., the importance of math competence in the science, technology, engineering, and mathematics disciplines, and the issue relating to math anxiety; Hagger et al., 2015; Ramirez et al., 2018). Second, students are often assigned more homework in math than in other subjects (Bempechat, 2019; Xu, 2015). Third, students' homework attitudes exert increasingly more significant influence on their homework behavior (Cooper et al., 1998). Yet, at the same time, their homework attitudes become more negative (Xu, 2004), and math value beliefs tend to decrease as they move from middle school to high school (Wigfield et al., 2015).

\section{Theoretical Background and Extant Literature}

Expectancy-value theory posits that achievement motivation includes two major constructs that are most directly related to achievement-related outcomes: expectancy and value (Eccles, 1983; Wigfield et al., 2015). Expectancy refers to the degree to which learners think that they can successfully execute a task, it focuses on the question "Can I do this task?" (Wigfield et al., 2015, p. 659). Value refers to the degree to which learners perceive a task is useful and worthwhile; it taps into the question "Do I Want to Do This Task?" (Wigfield et al., 2015, p. 659). In this theory, task value is postulated to have a positive influence on task effort, engagement, and completion, in the sense that learners who think that a task is useful and worthwhile are more likely to put forth effort and to be successful in the task. Therefore, based on expectancy-value theory, the value students place on homework as an achievementrelated task is "critical for ... the effort they will contribute to the endeavor and to the persistence they will display" (Warton, 2001, p. 157).

Existing literature, however, often focuses on the value of homework from adults' viewpoints (e.g., educators and parents; Cooper, 1989; Cooper et al., 2006; Epstein \& Van Voorhis, 2001; Rosário et al., 2019; Sun et al., 2020a, b; Xu, 2010). Epstein and Van Voorhis (2001) listed the following purposes, including preparation, practice, participation, study strategies, parent-child communication, parent-teacher communication, peer learning, policy directives, public relationship, and punishment. In a more recent study (Rosário et al., 2019), teachers focused on three major purposes for homework, including being aware of students' weakness and strengths, promotion of their involvement, and addressing their difficulties. However, many homework purposes viewed as important by adults (e.g., parent-teacher communication, public relation, and being aware of students' strengths) often matter little to students themselves (Warton, 2001; Xu, 2010).

Two exceptions to the near absence of research on students' viewpoints are one study with third graders (Xu \& Corno, 1998) and the other study with sixth to eighth graders (Xu \& Yuan, 2003). Parents and teachers in both studies mentioned two purposes for homework: academic (assisting students to better understand the materials covered in class), selfregulatory (assisting students to develop self-regulatory abilities including self-discipline and study skills). While students in both studies agreed with academic purpose with parents and teachers, they mentioned another purpose that was important for them - approval-seeking (to please parents and teachers, and to comply with their expectations). In addition, unlike $3 \mathrm{rd}$ graders (Xu \& Corno, 1998), certain students in grades 6-8 (Xu \& Yuan, 2003) mentioned self-regulatory purpose (e.g., "it [doing homework] makes you more responsible and independent").

Based on expectancy-value theory (Eccles, 1983; Eccles \& Wigfield, 2002) and extant literature tapping into homework purpose (Xu \& Corno, 1998; Xu \& Yuan, 2003), three recent studies validated math homework purposes reported by students (Sun et al., 2020a, b; Xu, 2021). Sun et al. (2020a) investigated the psychometric properties of the Math Homework Purpose Scale (MHPS) involving 5857 th graders. Having randomly split the sample into two groups, Sun et al. (2020a) carried out exploratory factor analysis (EFA) with one group $(n=293)$ and confirmatory factor analysis (CFA) with the other group $(n=292)$. Both EFA and CFA revealed that the MHPS contained three purposes: academic, self-regulatory, and approval-seeking. In another study involving 854 students in grade 9, Sun et al. (2020b) investigated the validity of scores on the MPHS. After randomly divided the sample into two groups, Sun et al. (2020b) carried out EFA with group 1 $(n=427)$ and CFA with group $2(n=427)$. Like the study by Sun et al. (2020a), both EFA and CFA indicated that the MHPS consisted of the same three purposes. Similarly, in the third study involving 1799 students in grades 10-11 (Xu, 2021), CFA results indicated that the MHPS included the same three purposes.

Across these validation studies (Sun et al., 2020a, b; Xu, 2021), although factor correlations between these purposes (academic, self-regulatory, and approval-seeking) were all significantly positive, the factor correlations between academic and self-regulatory were somewhat stronger than those between academic and approval-seeking, or between selfregulatory and approval seeking. Furthermore, academic purpose and self-regulatory purpose were more strongly related to homework effort and completion than approval-seeking purpose.

Taken together, existing literature on homework purposes has often centered on adults' perspectives (Cooper et al., 
2006; Rosário et al., 2019; Warton, 2001). One emerging line of research indicates that students did math homework for three major purposes (academic, self-regulatory, and approval-seeking), and that these purposes were positively related to homework effort and completion (Sun et al., 2020a, b; Xu, 2021). Although prior studies adopting a variable-centered approach offers insights into the direct links of each homework purpose with homework effort and completion, it ignores or overlooks the possibility that (a) students may have different purposes for homework simultaneously (e.g., Xu \& Corno, 1998; Xu \& Yuan, 2003), (b) distinct constellations or combination of homework purposes may coexist in the population, and (c) these distinct constellations may be associated with differences in other important external measures.

The importance of examining the combinations of homework purposes and their associated outcomes is further illustrated by findings from a recent study. Using a personcentered approach, Valle et al. (2019) identified four student profiles that differentially combined homework time and time management, and found "the most relevant variable when defining profiles as more or less effective is time management and not time spent on homework" (p. 425). In light of these findings, it would be intriguing to adopt a person-centered approach to identify student profiles that may differentially combine academic, self-regulatory, and approval-seeking purposes.

\section{The Current Investigation}

Provided that there is very little information on the purposes of students to get involved in homework, and none on how in combination they influence their behavior, the first goal of the present investigation was to identify homework purpose profiles in a sample of eleventh-grade students, concerning the likely combinations of academic, self-regulatory, and approval-seeking purposes. As this is the first study that we are aware of has used a person-centered approach to homework purposes with high school students, it is not clear how many homework purpose profiles might emerge.

Among these three purposes, academic and self-regulatory purposes can be considered as representing self-focused motive (e.g., more concerned with mastery and control of one's own experience), whereas approval-seeking purpose can be viewed as reflecting other-focused motive or social in nature (e.g., more driven by attachment or communal goals; Cooper et al., 2016; Sun et al., 2019). Thus, it is hypothesized that academic purpose and self-regulatory purpose may interact and combine within latent homework purpose profiles in that students with higher academic purpose are also more likely to have higher self-regulatory purpose. Meanwhile, we were less certain whether this would be the case with approval-seeking purpose. This is substantiated by findings from a longitudinal study (Sun et al., 2019) that academic purpose and self- regulatory purpose were positively and reciprocally related, whereas there was no support for any reciprocal influences of approval-seeking purpose and self-regulatory purpose (or academic purpose). This is further substantiated by validation studies (Sun et al., 2020a, b; Xu, 2021) in that latent correlation between approval-seeking purpose and self-regulatory purpose (or academic purpose) was substantially smaller than that between self-regulatory and academic purposes, and that self-regulatory and academic purposes (compared with approval-seeking purpose) were more strongly correlated with homework effort and completion.

Although student gender was not the focus of the present investigation, we examined whether it was related to profile membership, as (a) it was considered as an important variable in two theoretical models on homework (Cooper, 1989; Trautwein et al., 2006), and (b) it was examined in the three validation studies discussed above (Sun et al., 2020a, b; Xu, 2021). As the three validation studies with students in grade 7 (Sun et al., 2020a), grade 9 (Sun et al., 2020b), and grades 10$11(\mathrm{Xu}, 2021)$ found no significant latent mean differences in academic, self-regulatory, and approval-seeking purposes across gender, we hypothesized that student gender would not be related to profile membership.

The second goal of the current investigation was to examine how profile membership was related to homework effort and completion. Our justification for focusing on homework effort and completion is that they have been conceptualized as two critical variables in two theoretical models on homework (Cooper, 1989; Trautwein et al., 2006), and have received increasingly more attention in research literature (Cooper et al., 1998; Fan et al., 2017; Fernández-Alonso et al., 2015; Rodríguez et al., 2020; Rosário et al., 2018; Valle et al., 2019; $\mathrm{Xu}, 2011)$. In addition, homework effort and completion were the two external variables included in all three homework purpose validation studies discussed above (Sun et al., 2020a, b; Xu, 2021). Based on expectancy-value theory (e.g., task value; Eccles, 1983; Eccles \& Wigfield, 2002; Warton, 2001) and extant homework literature using variable-centered approach (Epstein \& Van Voorhis, 2012; Sun et al., 2020b; Xu, 2005), we hypothesized that, in general, students with higher levels of homework purposes would put forth more homework effort and complete more homework.

\section{Method}

\section{Participants and Procedure}

Participants were 750 high school students in grade 11 in southeast China (53.3\% female; $100 \%$ Han nationality). Across different areas in China, students often attended either regular schools or key schools based on criteria such as standardized achievement scores (Gao et al., 2011; Xu, 2020). 
Key schools typically selected about $10-15 \%$ more academically oriented students, while regular schools admitted about 85-90\% students with varying levels of academic preparation. For the present study, students were recruited from three regular high schools. We contacted and obtained approval from families for their children to participate in our current study. A trained assistant administered the measures (see next section) during normal school days, and teachers were requested to step out of classrooms during the administration. Taken together, the participation rate was $92.8 \%$.

The mean education level was 15.3 years $(S D=2.8)$ for fathers and 14.8 years $(S D=2.7)$ for mothers, and they were positively correlated $(r=.72, p<.01)$. Relating to math homework practices, almost all participants $(98.7 \%)$ worked on math assignments five or more days a week. They spent, on average, 71 mins $(S D=34)$ on math homework daily. These homework practices are generally parallel with related research with high school students in China (Xu et al., 2014).

\section{Measures}

Math Homework Purpose Scale (MHPS) This scale included academic, self-regulatory, and approval-seeking purposes (Sun et al., 2020a, b; Xu, 2021). Four items measured academic purpose, with respect to reinforcing school learning (e.g., "Doing math homework helps me prepare for the next class"). Three items assessed self-regulatory purpose, regarding developing desirable self-regulatory attributes (e.g., "Doing math homework helps develop good discipline"). Three items assessed approval-seeking purpose, concerning seeking approvals from parents, peers, and teachers (e.g., "Doing math homework brings me teacher approval"). Response format for these items varied from 1 (strongly disagree) to 4 (strongly agree). Using data from students in grades 10-11, Xu (2021) reported that homework purposes contained academic $(\alpha=.73 ; \omega=.74)$, self-regulatory $(\alpha=.87 ; \omega=.87)$, and approval-seeking $(\alpha=.93 ; \omega=.93$; SRMR $=.041 ; \mathrm{RMSEA}=.048 ; \mathrm{CFI}=.970 ; \mathrm{TLI}=.958)$. In the present study with 11th graders, homework purposes included academic $(\alpha=.73 ; \omega=.73 ; \mathrm{AVE}=.41 ; \mathrm{CRI}=.73)$, self-regulatory $(\alpha=.84 ; \omega=.84 ; \mathrm{AVE}=.64 ; \mathrm{CRI}=.84)$, and approval-seeking $(\alpha=.92 ; \omega=.92 ; \mathrm{AVE}=.80$; $\mathrm{CRI}=.92 ; \mathrm{SRMR}=.036 ; \mathrm{RMSEA}=.036 ; \mathrm{CFI}=.983$; $\mathrm{TLI}=.976)$.

Math Homework Effort Four items measured students' math homework effort, based on related on student effort in achievement related activities (e.g., Marsh et al., 2016), with math homework in particular (Trautwein et al., 2006; Xu, 2018; Yang \& Xu, 2018). These items focused on students' initiative to complete math homework (e.g., "I always try to finish my math assignments"; $\alpha=.80 ; \omega=.82 ; \mathrm{AVE}=.54$; $\mathrm{CRI}=.82 ; \mathrm{SRMR}=.013 ; \mathrm{RMSEA}=.042 ; \mathrm{CFI}=.993 ;$
$\mathrm{TLI}=.980$ ). Rating for these four items varied from 1 (strongly disagree) to 4 (strongly agree).

Math Homework Completion Students responded to one statement concerning homework completion, drawn from relevant studies (Cooper et al., 2006; Xu et al., 2019). It asked: "Some students often complete math homework on time, others rarely do. How much of your assigned math homework do you usually complete?" Response format included 1 (none), 2 (some), 3 (about half), 4 (most), and 5 (all). This item has been found to provide valid information relating to homework completion. For instance, $\mathrm{Xu}$ (2017) reported that, congruent with theoretical expectation, it was positively related to homework value and effort.

\section{Data Analyses}

LPA was applied to identify underlying latent subgroups of students according to the three homework purposes (academic, self-regulatory, and approval-seeking). Specifically, our analyses were based on the three standardized MHPS factor scores $(M=0, S D=1)$ as well as the standardized homework effort factor scores obtained from the CFA discussed in the previous section, using robust maximum likelihood estimator in Mplus 7.2.

Our decision for determining the optimal number of profiles was decided by a combination of fit indices, latent profile separation, parsimony, and interpretability (Nylund et al., 2007; Valle et al., 2019). They consisted of Akaike information criterion (AIC; Akaike, 1974), Bayesian information criterion (BIC; Schwartz, 1978), sample-adjusted Bayesian information criterion (SSABIC; Yang, 2006), Lo-Mendell-Rubin adjusted likelihood ratio test (LMRT; Lo et al., 2001), sample size for each profile, entropy value, and the interpretability of the solutions based on substantive theory.

In general, the solution with smaller AIC, BIC, and SSABIC shows better relative fit. A significant LMRT test indicates that a $\mathrm{K}$ profile model fits significantly better in comparison with a K-1 profile model. Profiles with less than 5\% of the sample are typically considered unsuitable and not feasible, reflecting excessive profiling extraction (Hipp \& Bauer, 2006; Wolter et al., 2019). Entropy value (from 0 to 1 ) is used to evaluate the classification accuracy of the solution $(>0.80$ reflecting high separation among profiles; Muthén \& Muthén, 2007; Ullrich-French \& Cox, 2020).

We carried out the covariate and distal outcome testing by applying a three-step procedure (Asparouhov \& Muthén, 2013, 2014). First, we performed LPA was with only the indicator variables to prevent other variables from influencing the classification of students into profiles. A "most likely class" variable was then developed according to the LPA, classifying each student to a profile with the highest 
likelihood. Finally, the auxiliary variables - covariate (gender) and distal outcome (homework effort and completion) - were included for examination after students had been classified to profiles so that the model would not change because of the auxiliary variables. In particular, we applied the R3STEP and DU3STEP in Mplus to carry out covariate and distal outcome testing (Muthén \& Muthén, 2013). To interpret the effect sizes, we adopted the following recommendations (Cohen, $1988)$, viewing $\eta^{2}=0.01 \quad(d=0.20), \eta^{2}=0.059(d=0.50)$, and $\eta^{2}=0.138(d=0.80)$ as reflecting a small, medium, and large effect size.

\section{Results}

Table 1 displays descriptive statistics of all measures, including means, standard deviations, skew, and kurtosis. Additionally, it displays Pearson correlations among all measures; all of them were significantly, positively correlated.

\section{Identification of Latent Profiles}

The fit of a number of profile models was evaluated (see Table 2), which was stopped in eight classes. First, based on multiple indices (AIC, BIC, SSA-BIC, LMRT, BLRT, and entropy), the four-profile model resulted in a better fit as compared with the two-profile model and the three-profile model. Although the five-, six-, seven-, and eight-profile models had lower AIC, BIC, and SSA-BIC values than the four-profile model, these models contained at least one profile less than $5 \%$ of the sample (see Table 2). Furthermore, a close examination of the five- and six-profile models indicated that these models did not provide distinctive information regarding the three homework purposes (e.g., in terms of standardized mean scores and relations with two external measures of homework effort and completion).

Regarding the classification accuracy of the four-profile solution, as displayed in Table 2, the entropy was 0.898 . Entropy is referred to "the overall degree of classification uncertainty in the solution" (Lanza \& Bray, 2010, p. 4), ranging from 0 (complete uncertainty) to 1 (complete certainty). Entropy values above 0.80 are typically viewed as adequate or high (Bonito, 2019; Clark \& Muthén, 2009). Table 3 included the classification accuracy of the four-profile model and the number of the students in each profile. The coefficients related to the profiles to which students were classified were presented on the main diagonal of the table. These coefficients ranged from $89.9 \%$ to $96.1 \%$, showing the robustness of the fourprofile solution.

\section{Description of the Four Profiles}

Table 4 displays the mean scores of students assigned to the four latent profiles. Profile 1 included $30.40 \%$ of the sample $(n=228)$ and was labelled as Low Profile because of their low mean scores on each of the three homework purposes $(z=$ -0.496 to -0.728 ; see Fig. 1 ). Profile 2 contained a large group of students $(54.40 \% ; n=408)$ and was labelled as Moderate Profile because their scores on each of homework purposes was close to the means $(z=0.195$ to 0.325 ; see Fig. 1). Profile 3 contained a small group of students $(5.73 \% ; n=$ 43) was labelled as Very Low Profile because of their very low mean scores on each of the three homework purposes $(z=$ -1.476 to -2.355 ; see Fig. 1). Profile 4 consisted of $9.47 \%$ of the sample $(n=71)$ and was labelled as High Profile because of their high means scores on each homework purpose ( $z=1.361$ to 1.876 ; see Fig. 1 ).

Figures 2, 3, and 4 presented three scatter plots - between academic purpose and self-regulatory purpose, between selfregulatory purpose and academic purpose, and between approval-seeking purpose and self-regulatory purpose. Taken together, these scatter plots indicated that the each profile could be adequately discriminated from the others.

\section{Gender and Latent Profiles of Homework Purpose}

Table 5 displays the results of the multinomial logistic regression model. Females were more likely than men in Profile 1
Table 1 Descriptive Statistics and Pearson Correlations Among the Measures

\begin{tabular}{llllllllll}
\hline Variable & $\mathrm{M}$ & $\mathrm{SD}$ & Skew & Kurtosis & 1 & 2 & 3 & 4 & 5 \\
\hline 1 Gender $^{\mathrm{a}}$ & 0.03 & 0.50 & -0.13 & -1.99 & - & & & \\
2 Academic purpose & 2.93 & 0.49 & -0.60 & 2.57 & $.13^{* *}$ & - & & & \\
3 Self-regulatory purpose & 2.69 & 0.65 & -0.31 & 0.51 & .06 & $.61^{* *}$ & - & & \\
4 Approval-seeking pur- & 2.21 & 0.70 & 0.26 & 0.14 & .00 & $.44^{* *}$ & $.52^{* *}$ & - & \\
$\quad$ pose & & & & & & & & & \\
5 Homework effort & 3.58 & 0.53 & -0.70 & 1.44 & .04 & $.31^{* *}$ & $.27^{* *}$ & $.09 *$ & - \\
6 Homework completion & 4.44 & 0.74 & -1.65 & 3.79 & $.10^{* *}$ & $.28^{* *}$ & $.20^{* *}$ & $.11^{* *}$ & $.41^{* *}$ \\
\hline
\end{tabular}

${ }^{\mathrm{a}}$ Gender was dummy coded $(-0.50=$ male; $0.50=$ female $)$

$N=750 .{ }^{*} p<.05 . * * p<.01$ 
Table 2 Fit Indices for Identifying Latent Profiles $(\mathrm{n}=750)$

\begin{tabular}{|c|c|c|c|c|c|c|c|c|}
\hline & \multicolumn{8}{|l|}{ Profiles } \\
\hline & 1 & 2 & 3 & 4 & 5 & 6 & 7 & 8 \\
\hline AIC & 6394.221 & 5931.267 & 5306.165 & 4961.366 & 4634.874 & 4472.831 & 4342.882 & 4216.732 \\
\hline $\mathrm{BIC}$ & 6421.942 & 5977.468 & 5370.846 & 5044.528 & 4736.516 & 4592.953 & 4481.484 & 4373.814 \\
\hline SSA-BIC & 6402.889 & 5945.714 & 5326.390 & 4987.371 & 4666.657 & 4510.393 & 4386.223 & 4265.851 \\
\hline Entropy & & 0.783 & 0.932 & 0.898 & 0.986 & 0.974 & 0.923 & 0.927 \\
\hline LMPT & & 453.817 & $610.064 * * *$ & $339.960 * *$ & $254.052 * * *$ & $163.855^{*}$ & 132.929 & 127.688 \\
\hline BLRT & & $470.954 * * *$ & $633.201 * * *$ & $352.798 * * *$ & $263.647 * * *$ & $170.043 * * *$ & $137.949 * * *$ & $132.510 * * *$ \\
\hline$n$ in each profile & $\mathrm{P} 1=750$ & $\mathrm{P} 1=145 \mathrm{P} 2=605$ & $\begin{array}{l}\mathrm{P} 1=98 \\
\mathrm{P} 2=581 \\
\mathrm{P} 3=71\end{array}$ & $\begin{array}{l}\mathrm{P} 1=228 \\
\mathrm{P} 2=408 \\
\mathrm{P} 3=43 \\
\mathrm{P} 4=71\end{array}$ & $\begin{array}{l}\mathrm{P} 1=59 \\
\mathrm{P} 2=48 \\
\mathrm{P} 3=196 \\
\mathrm{P} 4=419 \\
\mathrm{P} 5=28\end{array}$ & $\begin{array}{l}\mathrm{P} 1=61 \\
\mathrm{P} 2=363 \\
\mathrm{P} 3=174 \\
\mathrm{P} 4=45 \\
\mathrm{P} 5=28 \\
\mathrm{P} 6=79\end{array}$ & $\begin{array}{l}\mathrm{P} 1=76 \\
\mathrm{P} 2=45 \\
\mathrm{P} 3=58 \\
\mathrm{P} 4=290 \\
\mathrm{P} 5=79 \\
\mathrm{P} 6=174 \\
\mathrm{P} 7=28\end{array}$ & $\begin{array}{l}\mathrm{P} 1=45 \\
\mathrm{P} 2=268 \\
\mathrm{P} 3=95 \\
\mathrm{P} 4=79 \\
\mathrm{P} 5=58 \\
\mathrm{P} 6=152 \\
\mathrm{P} 7=25 \\
\mathrm{P} 8=28\end{array}$ \\
\hline Number of profiles with $n \leq 5 \%$ & 0 & 0 & 0 & 0 & 1 & 1 & 1 & 2 \\
\hline
\end{tabular}

AIC Akaike's Informational Criterion; BIC Bayesian Information Criterion; SSA-BIC Sample-Size Adjusted BIC; LMRT Lo-Mendell-Rubin adjusted maximum likelihood ratio test; $B L R T$ Parametric bootstrapped likelihood ratio test

$* p<.05 . * * p<.01 . * * * p<.001$

(Low; $b=1.162, \mathrm{SE}=0.399, p=.004, \mathrm{OR}=3.196$ ), Profile 2 (Moderate; $b=1.277, \mathrm{SE}=0.379, p=.001, \mathrm{OR}=3.586$ ), and Profile $4($ High $; b=0.907, \mathrm{SE}=0.440, p=.039, \mathrm{OR}=2.477)$ in reference to Profile 3 (Very Low).

\section{Profile Membership Relations to External Variables of Homework Effort and Completion}

The equality of the means of external variables of homework effort and completion across the four profiles. Table 6 shows the mean scores across the four profiles on homework effort and completion. Table 7 shows chi-square statistics for pairwise differences between latent profiles on homework effort and completion.

Taken together, results indicated that profile membership was significantly associated with homework effort and completion, with a medium effect size ( $d=0.466$ to 0.530$)$. With

Table 3 Description of Latent Profiles and Classification Accuracy of the Participants in Each Profile

\begin{tabular}{llllllrr}
\hline & \multicolumn{2}{l}{ Profiles } & \multicolumn{3}{c}{$\mathrm{n}$} & \multicolumn{1}{c}{$\%$} \\
\cline { 2 - 5 } & 1 & 2 & 3 & \multicolumn{1}{l}{4} & & \\
\hline 1. Low Profile & 0.899 & 0.093 & 0.008 & 0.000 & 228 & 30.40 \\
2. Moderate Profile & 0.042 & 0.956 & 0.000 & 0.002 & 408 & 54.40 \\
3. Very Low Profile & 0.041 & 0.000 & 0.959 & 0.000 & 43 & 5.73 \\
4. High Profile & 0.000 & 0.039 & 0.000 & 0.961 & 71 & 9.47 \\
\hline
\end{tabular}

respect to both homework effort and completion, High Profile and Moderate Profile had significantly high scores than Low Profile and Very Low Profile. In addition, Low Profile had significantly higher scores in homework completion than Very Low Profile. Although the differences in homework

Table 4 Description of Latent Profiles

\begin{tabular}{|c|c|c|c|c|}
\hline & \multirow[b]{2}{*}{ M } & \multirow[b]{2}{*}{ SE } & \multicolumn{2}{|c|}{ Confidence Intervals } \\
\hline & & & Lower $5 \%$ & Higher $5 \%$ \\
\hline \multicolumn{5}{|c|}{ Profile 1: Low Profile $(n=228)$} \\
\hline Academic & -0.613 & 0.065 & -0.721 & -0.506 \\
\hline Self-regulatory & -0.728 & 0.072 & -0.846 & -0.610 \\
\hline Approval-seeking & -0.496 & 0.060 & -0.594 & -0.398 \\
\hline \multicolumn{5}{|c|}{ Profile 2: Moderate Profile $(n=408)$} \\
\hline Academic & 0.250 & 0.033 & 0.195 & 0.304 \\
\hline Self-regulatory & 0.325 & 0.033 & 0.270 & 0.380 \\
\hline Approval-seeking & 0.195 & 0.048 & 0.116 & 0.273 \\
\hline \multicolumn{5}{|c|}{ Profile 3: Very Low Profile $(n=43)$} \\
\hline Academic & -2.187 & 0.252 & -2.602 & -1.773 \\
\hline Self-regulatory & -2.355 & 0.124 & -2.560 & -2.151 \\
\hline Approval-seeking & -1.476 & 0.111 & -1.659 & -1.293 \\
\hline \multicolumn{5}{|c|}{ Profile 4: High Profile $(n=71)$} \\
\hline Academic & 1.852 & 0.076 & 1.727 & 1.977 \\
\hline Self-regulatory & 1.876 & 0.053 & 1.789 & 1.962 \\
\hline Approval-seeking & 1.361 & 0.172 & 1.078 & 1.644 \\
\hline
\end{tabular}


Fig. 1 Latent profile analysis of homework purposes: Four-profile solution effort and completion between High Profile and Moderate Profile were not statistically significant, a clear trend was observed in that High Profile had higher scores in these two external measures than Moderate Profile.

\section{Discussion}

The current study extends extant literature on homework purpose, by using a person-centered approach to identify the possible combinations of homework purposes in eleventh-grade students and to examine difference between the empirically derived profiles. Results from LPA revealed that four different profiles of students were identified: Very Low Profile (very low in all purposes; 5.73\%), Low Profile (low in all purposes; $30.40 \%$ ), Moderate Profile (moderate in all purposes; 54.40\%), and High Profile (high in all purposes; 9.47\%). Results further revealed that females were more than two to three times as likely in Low, Moderate, or High Profiles than in Very Low Profile.

The current study takes another step forward, by examining the differences in homework behavior as a function of the profile membership. In line with theoretical expectations and previous studies using a variable-centered approach (Eccles,
1983; Eccles \& Wigfield, 2002; Epstein \& Van Voorhis, 2012; Sun et al., 2020b; Xu, 2005), results revealed that profile membership was significantly related to homework effort and completion, with a medium effect size. Specifically, the profile of students with higher homework purposes (e.g., High Profile and Moderate Profile) were those who put forth more homework effort and completed more homework assignments. In contrast, the profile of students with lowest homework purposes (i.e., Very Low Profile) were those who put forth least homework effort and completed least homework assignments.

Our results concerning the four homework purpose profiles, and their relations with covariate (gender) and distal outcome (homework effort and completion) suggests that (a) homework purposes from students' perspectives matter in their homework behavior, (b) student gender was related to profile membership, and (c) students with high or low level of one purpose (e.g., self-regulatory) are related to a high or low level of other purposes (e.g., academic and approval-seeking). These results based on a person-centered approach provide a deeper understanding of how these three homework purposes coexist within students, moving beyond stating if these purposes are correlated or if each purpose is related to homework behavior (e.g., homework completion). 
Fig. 2 Scatter plot between academic purpose and selfregulatory purpose

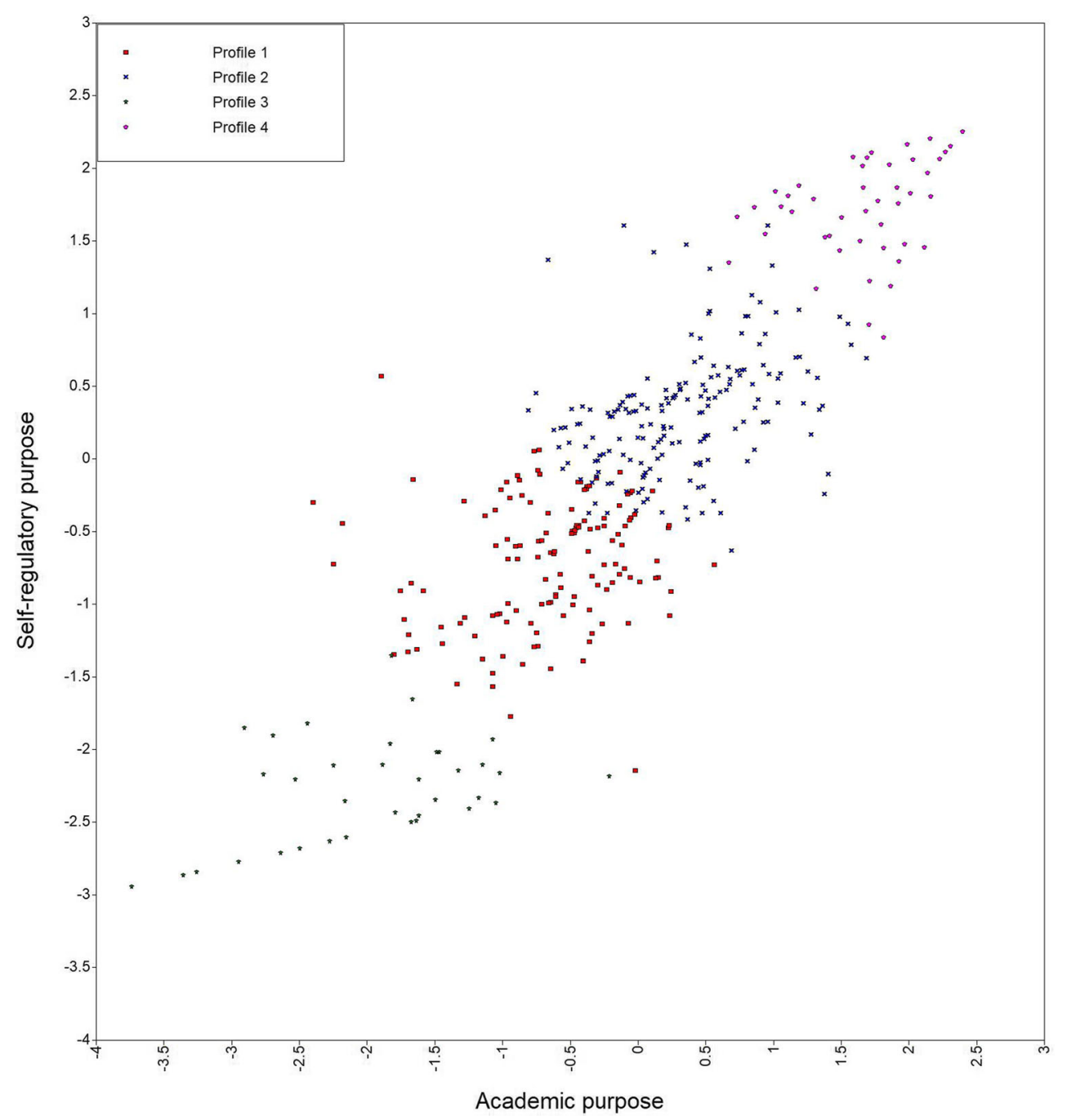

Specifically, the current study revealed that there were no overlapping or non-linear profiles of students relatively higher on one homework purpose (e.g., academic) yet relatively lower on other homework purposes (e.g., self-regulatory and approval-seeking). That is, the relation between the three homework purposes appeared to be straightforwardly linear. This finding is partially consistent with our hypothesis that students relatively higher in academic purpose would be relatively higher in self-regulatory purpose, as both academic purpose and self-regulatory purpose reflect self-focused motive (Cooper et al., 2016; Sun et al., 2019). On the other hand, we were less certain whether students relatively higher in academic purpose (or self-regulatory purpose) would be relatively higher in approval-seeking purpose, as approvalseeking purpose represents other-focused motive (Cooper et al., 2016; Sun et al., 2019).

One possible explanation for our finding (i.e., no overlapping profiles) is that academic and self-regulatory purposes may have become relatively less self-focused (or more other-focused) in collectivist cultures such as China, where the self is largely defined by relations with others (Chen et al., 2006), and where independence is less highly valued than interdependence, harmony, conformity, and in-group approval and cohesion (Epstein et al., 2014; Hofstede, 2003). Given that this is the first study that has used a personcentered to homework purposes (including both self- and other-focused motives), it would be theoretically and practically important to pursue this line of investigation in individualist cultures to see whether there would be overlapping profiles of students (e.g., relatively higher on self-focused motive but relatively lower on other-focused motive).

With respect to gender differences in academic, self-regulatory, and approval-seeking purposes, prior studies using a variable-centered approach did not report any significant latent mean differences in all three purposes across gender (Sun et al., 2020a, b; Xu, 2021). Using a person-centered approach, the present study extended previous research by showing that females were more than two to three times as likely in Low, 
Fig. 3 Scatter plot between selfregulatory purpose and approvalseeking purpose

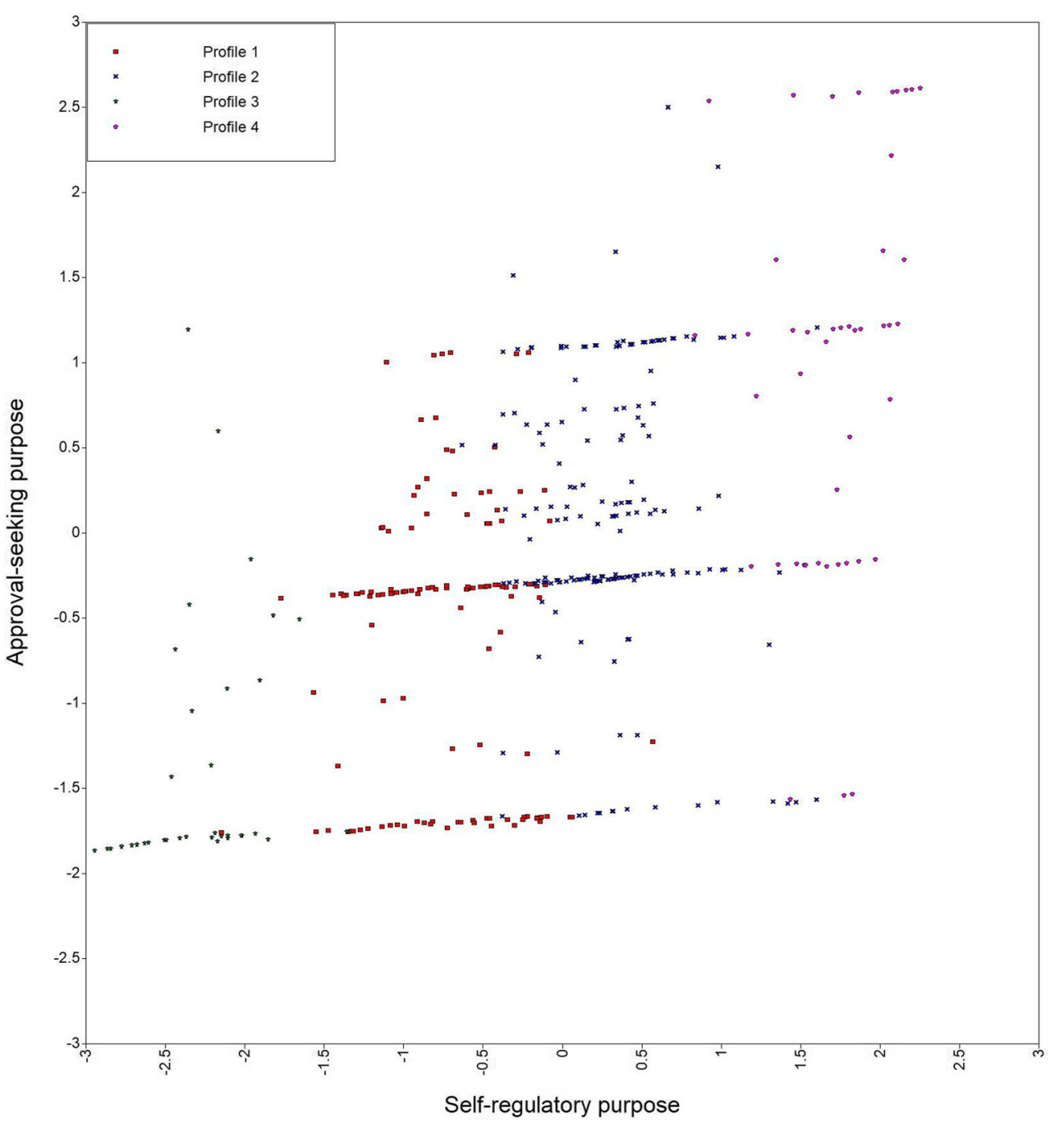

Moderate, or High Profiles than in Very Low Profile. Although not the focus of the current investigation, this is an interesting finding to be followed in future investigation, particularly in conjunction with the line of research discussed in the previous paragraph (i.e., relating to possible overlapping profiles of students in individualist cultures).

Consequently, it would be highly desirable to simultaneously attend to all three homework purposes perceived by students (academic, self-regulatory, and approval-seeking), as students with a high level of one purpose (e.g., academic) tend to have a high level of other purposes (self-regulatory and approval-seeking). Teachers and parents may want to be more consciously aware of the types of homework assignments, homework feedback, and homework support most likely lead to academic improvement, development of self-regulatory capacities, and gaining their (genuine) approval at the same time.

Meanwhile, our results that students had distinct homework purpose profiles suggest that teacher and parents need to pay differentiated attention to students in different profiles. Students in High Profile or Moderate Profile may need less external support from teachers and parents, yet encouraging them to share the value of homework from their perspectives are likely to be beneficial for students in this profile as well as for students in other profiles. For remaining students in Very Low Profile and Low Profile, it would be beneficial, for example, for teachers to carefully designing and selecting highquality homework assignments to illustrate to students the connection among homework, self-regulation (e.g., time management), and academic improvement. It would also beneficial for teachers to provide adaptive feedback and ongoing support according to the needs of students in different profiles to promote their homework effort and completion. In addition, it would be beneficial to provide professional development for teachers, as preservice and inservice teacher education have largely centered on the quality of classroom practice (e.g., teaching strategies, instructional materials, feedback, and assessment), yet not on the quality of homework practice such as 
Fig. 4 Scatter plot between approval-seeking purpose and academic purpose

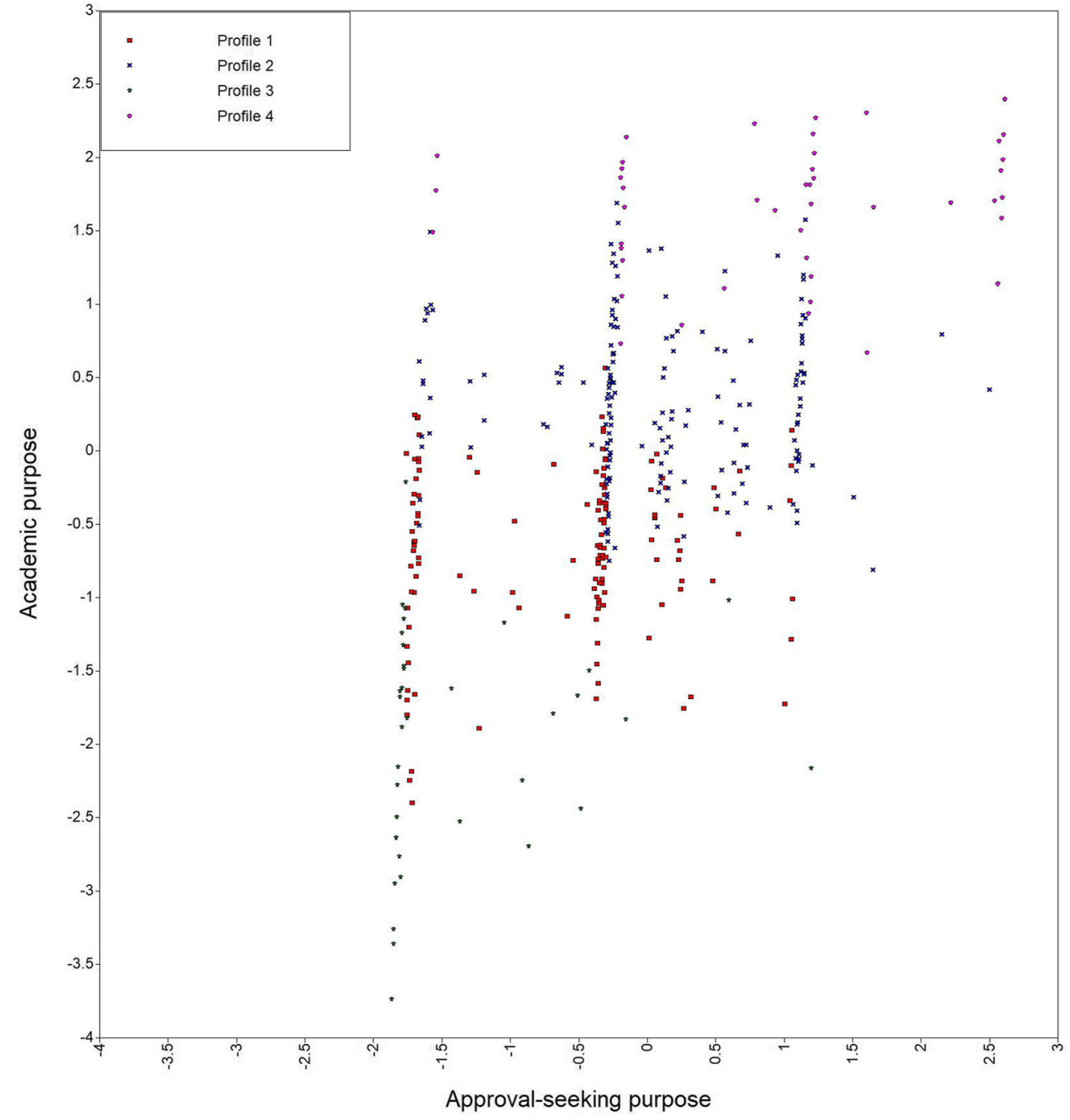

Table 5 Results of Multinomial Logistic Regression Analysis on Gender

\begin{tabular}{lllllll}
\hline Reference Profile & & Estimate & S.E. & \multicolumn{1}{c}{$\begin{array}{l}\text { Est./ } \\
\text { S.E. }\end{array}$} & $p$ & Odds Ratio \\
\hline Profile 1: Low & & & & & & \\
& & & & & & \\
& Profile 2: Moderate & 0.116 & 0.194 & 0.597 & 0.550 & 1.123 \\
& Profile 3: Very Low & -1.162 & 0.399 & -2.913 & 0.004 & 0.313 \\
& Profile 4: High & -0.255 & 0.288 & -0.885 & 0.376 & 0.775 \\
Profile 2: Moderate & & & & & & \\
& Profile 1: Low & -0.116 & 0.194 & -0.597 & 0.550 & 0.890 \\
& Profile 3: Very Low & -1.277 & 0.379 & -3.373 & 0.001 & 0.279 \\
& Profile 4: High & -0.371 & 0.271 & -1.368 & 0.171 & 0.690 \\
& & & & & & \\
& Profile 3: Very Low & 1.162 & 0.399 & 2.913 & 0.004 & 3.196 \\
& Profile 2: Moderate & 1.277 & 0.379 & 3.373 & 0.001 & 3.586 \\
& Profile 4: High & 0.907 & 0.440 & 2.059 & 0.039 & 2.477 \\
\hline
\end{tabular}


Table 6 Mean Scores Across Latent Profiles on Homework Effort and Homework Completion $(\mathrm{n}=750)$

\begin{tabular}{|c|c|c|c|c|c|c|}
\hline & $\begin{array}{l}\text { Profile 1: Low } \\
(n=228) \\
M(S E)\end{array}$ & $\begin{array}{l}\text { Profile 2: Moderate } \\
(n=408) \\
\mathrm{M}(\mathrm{SE})\end{array}$ & $\begin{array}{l}\text { Profile 3: Very Low } \\
(n=43) \\
\mathrm{M}(\mathrm{SE})\end{array}$ & $\begin{array}{l}\text { Profile 4: High } \\
(n=71) \\
\text { M (SE) }\end{array}$ & $\begin{array}{l}\text { Overall chi-square test } \\
\text { value }(d f=3)\end{array}$ & $\begin{array}{l}\text { Effect } \\
\text { size }(d)\end{array}$ \\
\hline $\begin{array}{c}\text { Homework } \\
\text { effort }\end{array}$ & $-0.21^{\mathrm{a}}(0.06)$ & $0.18^{\mathrm{b}}(0.06)$ & $-0.66^{\mathrm{a}}(0.22)$ & $0.46^{\mathrm{b}}(0.15)$ & $38.576^{* * *}$ & 0.466 \\
\hline $\begin{array}{l}\text { Homework } \\
\text { completion }\end{array}$ & $4.30^{\mathrm{b}}(0.06)$ & $4.61^{\mathrm{c}}(0.03)$ & $3.73^{\mathrm{a}}(0.23)$ & $4.67^{\mathrm{c}}(0.08)$ & $48.749 * * *$ & 0.527 \\
\hline
\end{tabular}

$\dagger$ Standardized factor scores $(M=0, S D=1)$

Means with the same superscript in a column are not statistically different at $\alpha>.01$

$* * * p<.001$

homework quality and the quality of homework feedback (Rosário et al., 2018; Xu, 2016).

Certain limitations needs to be acknowledged. First, the present study was limited to cross-sectional data. Second, it was limited to math homework, involving Chinese high school students. Finally, although the present study incorporate student gender as one covariate, it did not incorporate other covariates in the homework process such as prior achievement and socio-economic status.

As this is the first study that has used a person-centered approach to homework purposes perceived by high school students, it would be beneficial to pursue this line of research involving elementary and middle school students and in other achievement domains, as there are developmental differences in task value perceived by students across achievement domains (e.g., sports and foreign language; Jacobs et al., 2002). Additionally, it would be informative to include other important outcome variables in the homework process such as homework self- regulation strategies (e.g., time management and help seeking) and student achievement. Similarly, it would be informative to include other covariates such as prior achievement, socio-economic status, and teacher homework involvement. Furthermore, as discussed above, it would be important to pursue this line of research in cross-cultural environments, as homework purposes perceived by students may be affected by cultural differences (e.g., regarding self-focused and other-focused motives, and the value of homework and persistence; Cooper et al., 2016; King et al., 2014; Sun et al., 2019). Finally, it would be highly beneficially to pursue this line of research in online settings, because COVID-19 has prompted 'an unprecedented massive 'migration' from traditional in-class face-to-face education to online education" (Bao, 2020, p. 113), and because online homework presents new motivational challenges for many students (e.g., concern over the usefulness and worth of online assignments; Bowman et al., 2014; Yushau \& Khan, 2014).
Table 7 Chi-Square Test Statistics for Pairwise Differences Between Latent Profiles

\begin{tabular}{|c|c|c|}
\hline & Profile Comparison & Chi-Square Test Statistic, $p$ value \\
\hline \multirow[t]{6}{*}{ Homework effort } & 1 (Low) vs. 2 (Moderate) & $16.587, p<.001$ \\
\hline & 1 (Low) vs. 3 (Very Low) & $3.492, p=.062$ \\
\hline & 1 (Low) vs. 4 (High) & $17.903, p<.001$ \\
\hline & 2 (Moderate) vs. 3 (Very Low) & $13.227, p=.001$ \\
\hline & 2 (Moderate) vs. 4 (High) & $3.311, p=.069$ \\
\hline & $3($ Very low $)$ vs. 4 (High) & $17.700, p<.001$ \\
\hline \multirow[t]{6}{*}{ Homework completion } & 1 (Low) vs. 2 (Moderate) & $16.751, p<.001$ \\
\hline & 1 (Low) vs. 3 (Very Low) & $4.942, p=.026$ \\
\hline & 1 (Low) vs. 4 (High) & $13.090, p<.001$ \\
\hline & 2 (Moderate) vs. 3 (Very Low) & $15.234, p<.001$ \\
\hline & 2 (Moderate) vs. 4 (High) & $0.444, p=.505$ \\
\hline & 3 (Very Low) vs. 4 (High) & $15.582, p<.001$ \\
\hline
\end{tabular}


Data Availability The data supporting the results of this study are available from the corresponding author upon reasonable request.

\section{Declarations}

Conflict of Interest The author declares no conflict of interest.

Human Rights The study was compliant with the ethical standards of the institutional and national research committee, and with the 1964 Helsinki declaration and its amendments or comparable ethical standards.

Informed Consent Informed consent was obtained from participants in the present investigation.

\section{References}

Akaike, H. (1974). A new look at statistical model identification. IEEE Transactions on Automatic Control, 19, 716-723. https://doi.org/ 10.1109/TAC.1974.1100705.

Asparouhov, T., \& Muthén, B. O. (2013). Auxiliary variables in mixture modeling: 3-step approaches using Mplus. Mplus web notes, 15, 124.

Asparouhov, T., \& Muthén, B. (2014). Auxiliary variables in mixture modeling: Three-step approaches using Mplus. Structural Equation Modeling, 21, 329-341. https://doi.org/10.1080/ 10705511.2014.915181.

Bao, W. (2020). COVID-19 and online teaching in higher education: A case study of Peking University. Human Behavior and Emerging Technologies, 2(2), 113-115. https://doi.org/10.1002/hbe2.191.

Bempechat, J. (2019). The case for (quality) homework: Why it improves learning, and how parents can help. Education Next, 19(1), 36-44.

Bonito, J. A. (2019). A bottom-up approach to examining group-level communication patterns: A multilevel latent profile analysis of functional group interaction. Human Communication Research, 45(2), 202-225. https://doi.org/10.1093/hcr/hqy020.

Bowman, C. R., Gulacar, O., \& King, D. B. (2014). Predicting student success via online homework usage. Journal of Learning Design, $7(2), 47-61$.

Chen, H., Jackson, T., \& Huang, X. (2006). The negative physical self scale: Initial development and validation in samples of Chinese adolescents and young adults. Body Image, 3(4), 401-412. https://doi. org/10.1016/j.bodyim.2006.07.005.

Clark, S. L., \& Muthén, B. (2009). Relating latent class analysis results to variables not included in the analysis. Available at: http://statmodel. com/download/relatinglca.pdf. Accessed 11 Jun 2021.

Cohen, J. (1988). Statistical power analysis for the behavioral sciences. Lawrence Erlbaum.

Cooper, H. (1989). Homework. Longman.

Cooper, H., Lindsay, J. J., Nye, B., \& Greathouse, S. (1998). Relationships among attitudes about homework, amount of homework assigned and completed, and student achievement. Journal of Educational Psychology, 90, 70-83. https://doi.org/10.1037/00220663.90.1.70.

Cooper, H., Robinson, J. C., \& Patall, E. A. (2006). Does homework improve academic achievement? A synthesis of research, 19872003. Review of Educational Research, 76, 1-62. https://doi.org/ 10.3102/00346543076001001.

Cooper, M. L., Kuntsche, E., Levitt, A., Barber, L., \& Wolf, S. (2016). A motivational perspective on substance use: Review of theory and research. In K. J. Sher (Ed.), Oxford handbook of substance use disorders (pp. 375-421). Oxford University Press.
Corno, L. (2011). Studying self-regulation habits. In B. J. Zimmerman \& D. H. Schunk (Eds.), Handbook of self-regulation of learning and performance (pp. 361-375). Routledge.

Corno, L., \& Xu, J. (2004). Doing homework as the job of childhood. Theory Into Practice, 43, 227-233. https://doi.org/10.1207/ s15430421tip4303_9.

Eccles, J. S. (1983). Expectancies, values and academic behaviors. In J. T. Spence (Ed.), Achievement and achievement motives: Psychological and sociological approaches (pp. 75-146). Freeman.

Eccles, J. S., \& Wigfield, A. (2002). Motivational beliefs, values, and goals. Annual Review of Psychology, 53, 109-132. https://doi.org/ 10.1146/annurev.psych.53.100901.135153.

Epstein, J. L., \& Van Voorhis, F. L. (2001). More than minutes: Teachers' roles in designing homework. Educational Psychologist, 36, 181193. https://doi.org/10.1207/S15326985EP3603 4.

Epstein, J. L., \& Van Voorhis, F. (2012). The changing debate: From assigning homework to designing homework. In S. Suggate \& E. Reese (Eds.), Contemporary debates in child development and education (pp. 263-273). Routledge.

Epstein, N. B., Curtis, D. S., Edwards, E., Young, J. L., \& Zheng, L. (2014). Therapy with families in China: Cultural factors influencing the therapeutic alliance and therapy goals. Contemporary Family Therapy, 36(2), 201-212. https://doi.org/10.1007/s10591-0149302-x.

Fan, H., Xu, J., Cai, Z., He, J., \& Fan, X. (2017). Homework and students' achievement in math and science: A 30-year meta-analysis, 19862015. Educational Research Review, 20, 35-54. https://doi.org/10. 1016/j.edurev.2016.11.003.

Fernández-Alonso, R., Suárez-Álvarez, J., \& Muñiz, J. (2015). Adolescents' homework performance in mathematics and science: Personal factors and teaching practices. Journal of Educational Psychology, 107, 1075-1085. https://doi.org/10.1037/edu0000032.

Gao, X., Barkhuizen, G., \& Chow, A. (2011). 'Nowadays, teachers are relatively obedient': Understanding primary school English teachers' conceptions of and drives for research in China. Language Teaching Research, 15, 61-81. https://doi.org/10.1177/ 1362168810383344

Hagger, M. S., Sultan, S., Hardcastle, S. J., \& Chatzisarantis, N. L. (2015). Perceived autonomy support and autonomous motivation toward mathematics activities in educational and out-of-school contexts is related to mathematics homework behavior and attainment. Contemporary Educational Psychology, 41, 111-123. https://doi. org/10.1016/j.cedpsych.2014.12.002.

Hipp, J. R., \& Bauer, D. J. (2006). Local solutions in the estimation of growth mixture models. Psychological Methods, 11, 36-53. https:// doi.org/10.1037/1082-989X.11.1.36.

Hofstede, G. (2003). Cultures and organizations: Software of the mind. Profile Books.

Jacobs, J. E., Lanza, S., Osgood, D. W., Eccles, J. S., \& Wigfield, A. (2002). Changes in children's self-competence and values: Gender and domain differences across grades one through twelve. Child Development, 73, 509-527. https://doi.org/10.1111/1467-8624. 00421.

King, R. B., Ganotice, F. A., \& Watkins, D. A. (2014). A cross-cultural analysis of achievement and social goals among Chinese and Filipino students. Social Psychology of Education, 17, 439-455. https://doi.org/10.1007/s11218-014-9251-0.

Lanza, S. T., \& Bray, B. C. (2010). Transitions in drug use among highrisk women: An application of latent class and latent transition analysis. Advances and Applications in Statistical Sciences, 3(2), 203235.

Lo, Y., Mendell, N. R., \& Rubin, D. B. (2001). Testing the number of components in a normal mixture. Biometrika, 88, 767-778. https:// doi.org/10.1093/biomet/88.3.767.

Marsh, H. W., Pekrun, R., Lichtenfeld, S., Guo, J., Arens, A. K., \& Murayama, K. (2016). Breaking the double-edged sword of effort/ 
trying hard: Developmental equilibrium and longitudinal relations among effort, achievement, and academic self-concept. Developmental Psychology, 52, 1273-1290. https://doi.org/10. 1037/dev0000146.

Muthén, L. K., \& Muthén, B. O. (2007). Online comment Re: what is a good value of entropy? Retrieved from http://www.statmodel.com/ discussion/messages/13/2562.html?1237580237. Accessed 11 Jun 2021.

Muthén, L. K., \& Muthén, B. O. (2013). Version 7.1 Mplus Language Addendum. Retrieved from http://www.statmodel.com/download/ Version7.1xLanguage.pdf.

Nylund, K. L., Asparouhov, T., \& Muthén, B. O. (2007). Deciding on the number of classes in latent class analysis and growth mixture modeling: A Monte Carlo simulation study. Structural Equation Modeling, 14, 535-569. https://doi.org/10.1080/ 10705510701575396.

Ramirez, G., Shaw, S. T., \& Maloney, E. A. (2018). Math anxiety: Past research, promising interventions, and a new interpretation framework. Educational Psychologist, 53(3), 145-164. https://doi.org/10. 1080/00461520.2018.1447384.

Rodríguez, S., Piñeiro, I., Regueiro, B., \& Estévez, I. (2020). Intrinsic motivation and perceived utility as predictors of student homework engagement. Revista de Psicodidáctica, 25, 93-99. https://doi.org/ 10.1016/j.psicod.2019.11.001

Rosário, P., Núñez, J. C., Vallejo, G., Nunes, T., Cunha, J., Fuentes, S., \& Valle, A. (2018). Homework purposes, homework behaviors, and academic achievement. Examining the mediating role of students' perceived homework quality. Contemporary Educational Psychology, 53, 168-180. https://doi.org/10.1016/j.cedpsych.2018. 04.001 .

Rosário, P., Cunha, J., Nunes, A. R., Moreira, T., Núñez, J. C., \& Xu, J. (2019). "Did you do your homework?" mathematics teachers' homework follow-up practices at middle school level. Psychology in the Schools, 56, 92-108. https://doi.org/10.1002/pits.22198.

Schwartz, G. (1978). Estimating the dimension of a model. Annals of Statistics, 6, 461-464. https://doi.org/10.1214/aos/1176344136.

Sun, M., Du, J., \& Xu, J. (2019). Are homework purposes and student achievement reciprocally related? A longitudinal study. Current Psychology. https://doi.org/10.1007/s12144-019-00447-y.

Sun, M., Du, J., \& Xu, J. (2020a). Math homework purpose scale for preadolescents: A psychometric evaluation. Current Psychology, 39, 1740-1748. https://doi.org/10.1007/s12144-018-9870-2.

Sun, M., Du, J., \& Xu, J. (2020b). Math homework purpose scale: Measurement invariance and latent mean differences across gender. Swiss Journal of Psychology, 79, 47-54. https://doi.org/10.1024/ 1421-0185/a000234.

Trautwein, U., Lüdtke, O., Schnyder, I., \& Niggli, A. (2006). Predicting homework effort: Support for a domain-specific, multilevel homework model. Journal of Educational Psychology, 98, 438-456. https://doi.org/10.1037/0022-0663.98.2.438.

Ullrich-French, S., \& Cox, A. E. (2020). The use of latent profiles to explore the multi-dimensionality of self-compassion. Mindfulness, 11, 1483-1499. https://doi.org/10.1007/s12671-020-01365-y.

Valle, A., Piñeiro, I., Rodríguez, S., Regueiro, B., Freire, C., \& Rosário, P. (2019). Time spent and time management in homework in elementary school students: A person-centered approach. Psicothema, 31, 422-428. https://doi.org/10.7334/psicothema2019.191.

Van Voorhis, F. L. (2004). Reflecting on the homework ritual: Assignments and designs. Theory Into Practice, 43, 205-212. https://doi.org/10.1207/s15430421 tip4303 6 .

Warton, P. M. (2001). The forgotten voices in homework: Views of students. Educational Psychologist, 36, 155-165. https://doi.org/ $10.1207 / \mathrm{S} 15326985 \mathrm{EP} 36032$.

Wigfield, A., Eccles, J. S., Fredricks, J. A., Simpkins, S., Roeser, R. W., \& Schiefele, U. (2015). Development of achievement motivation and engagement. In M. E. Lamb \& R. M. Lerner (Eds.),
Handbook of child psychology and developmental science, Vol. 3. Socioemotional processes (7th ed., pp. 657-700). Wiley.

Wolter, I., Ehrtmann, L., Seidel, T., \& Drechsel, B. (2019). Social or economic goals? The professional orientation of students enrolled in STEM and non-STEM majors in university. Frontiers in Psychology, 10, 2065. https://doi.org/10.3389/fpsyg.2019.02065.

$\mathrm{Xu}, \mathrm{J}$. (2004). Family help and homework management in urban and rural secondary schools. Teachers College Record, 106, 1786-1803. https://doi.org/10.1111/j.1467-9620.2004.00405.x.

$\mathrm{Xu}, \mathrm{J}$. (2005). Purposes for doing homework reported by middle and high school students. Journal of Educational Research, 99, 46-55. https://doi.org/10.3200/JOER.99.1.46-55.

$\mathrm{Xu}$, J. (2010). Homework purpose scale for high school students: A validation study. Educational and Psychological Measurement, 70, 459-476. https://doi.org/10.1177/0013164409344517.

$\mathrm{Xu}, \mathrm{J}$. (2011). Homework completion at the secondary school level: A multilevel analysis. Journal of Educational Research, 104(3), 171182. https://doi.org/10.1080/00220671003636752.

$\mathrm{Xu}, \mathrm{J}$. (2015). Investigating factors that influence conventional distraction and tech-related distraction in math homework. Computers \& Education, 81, 304-314. https://doi.org/10.1016/j.compedu.2014. 10.024

$\mathrm{Xu}$, J. (2016). A study of the validity and reliability of the teacher homework involvement scale: A psychometric evaluation. Measurement, 93, 102-107. https://doi.org/10.1016/j.measurement.2016.07.012.

$\mathrm{Xu}, \mathrm{J}$. (2017). Homework expectancy value scale for high school students: Measurement invariance and latent mean differences across gender and grade level. Learning and Individual Differences, 60 , 10-17. https://doi.org/10.1016/j.lindif.2017.10.003.

$\mathrm{Xu}, \mathrm{J}$. (2018). Reciprocal effects of homework self-concept, interest, effort, and math achievement. Contemporary Educational Psychology, 55, 42-52. https://doi.org/10.1016/j.cedpsych.2018.09.002.

$\mathrm{Xu}$, J. (2020). Longitudinal effects of homework expectancy, value, effort, and achievement: An empirical investigation. International Journal of Educational Research, 99, 101507. https://doi.org/10. 1016/j.ijer.2019.101507.

$\mathrm{Xu}$, J. (2021). Math homework purpose Scale: Confirming the factor structure with high school students. Psychology in the Schools. https://doi.org/10.1002/pits.22507.

Xu, J., \& Corno, L. (1998). Case studies of families doing third-grade homework. Teachers College Record, 100, 402-436.

Xu, J., \& Yuan, R. (2003). Doing homework: Listening to students', parents', and teachers' voices in one urban middle school community. School Community Journal, 13(2), 25-44.

Xu, J., Yuan, R., Xu, B., \& Xu, M. (2014). Modeling students' time management in math homework. Learning and Individual Differences, 34, 33-42. https://doi.org/10.1016/j.lindif.2014.05. 011.

Xu, J., Du, J., Liu, F., \& Huang, B. (2019). Emotion regulation, homework completion, and math achievement: Testing models of reciprocal effects. Contemporary Educational Psychology, 59, 101810. https://doi.org/10.1016/j.cedpsych.2019.101810.

Yang, C. (2006). Evaluating latent class analysis models in qualitative phenotype identification. Computational Statistics \& Data Analysis, 50, 1090-1104. https://doi.org/10.1016/j.csda.2004.11.004.

Yang, F., \& Xu, J. (2018). Homework expectancy value scale: Measurement invariance and latent mean differences across gender. Journal of Psychoeducational Assessment, 36, 863-868. https://doi. org $/ 10.1177 / 0734282917714905$.

Yushau, B., \& Khan, M. A. (2014). Student perceptions of online homework in preparatory year pre-calculus courses. International Journal of Mathematics Trends and Technology, 8(1), 12-17.

Publisher's Note Springer Nature remains neutral with regard to jurisdictional claims in published maps and institutional affiliations. 